\title{
Correction: Investigation of High Temperature Performance and Viscosity Characteristics of Modified and Unmodified Color Asphalt
}

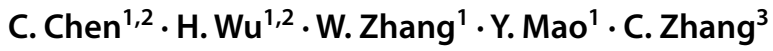 \\ Published online: 4 March 2022 \\ (c) The Society for Experimental Mechanics, Inc 2022
}

Correction: Experimental Techniques (2021) 46:317-333

https://doi.org/10.1007/s40799-021-00507-8

The article, Investigation of High Temperature Performance and Viscosity Characteristics of Modified and Unmodified Color Asphalt, by C. Chen, H. Wu, and C. Zhang, was submitted and accepted for publication in a special issue on "Computations \& Experiments on Dynamics of Complex Fluids and Structure." It was included in the April 2022 issue of Experimental Techniques due to an error in production. When the special issue is published, there will be a statement and reference to the previously published article.

Publisher's Note Springer Nature remains neutral with regard to jurisdictional claims in published maps and institutional affiliations.

The original article can be found online at https://doi.org/10.1007/ s40799-021-00507-8.

C. Chen

chenchengqin@126.com

$\triangle \mathrm{H} . \mathrm{Wu}$

79594386@qq.com

W. Zhang

zw4241261@126.com

Y. Mao

147184602@qq.com

C. Zhang

374931526@qq.com

1 School of Civil Engineering, Northwest Minzu University, Lanzhou 730124, China

2 Key Laboratory of New Building Materials and Building Energy Efficiency of Gansu Province, Lanzhou 730124, China

3 Gansu Provincial Transportation Research Institute Group Co., Ltd, Lanzhou 730000, China 